\title{
Five-Year Survival Rate and the Factors for Risk-Directed Therapy in Acute Lymphoblastic Leukemia
}

\begin{abstract}
Background: Acute lymphoblastic leukemia (ALL) has 5-year survival of more than $90 \%$ in many advanced cancer research institutes. However, advanced cancer care is not available to majority of poor in developing countries. The experience of treating such patients in a resource-scarce setting is described herewith. Of the 75 individuals studied, $11 \%$ of the children were stunted, $>21 \%$ were underweight, and $16 \%$ of the under-five children had acute malnutrition. Massive hepatosplenomegaly and lymphadenopathy were present in $75 \%$ and $77 \%$ children, respectively. About $71 \%$ patients achieved complete remission (CR). A total of $30(40 \%)$ children lived for $>5$ years after diagnosis and $21(28 \%)$ of them had event-free 5 years. Weight for height for under-five children $(P=0.029)$ and total count $(P=0.019)$ were found to be significantly associated with deaths during induction. Weight for age $(P=0.024)$, weight for height of under-five children $(P=0.009)$, and lymphadenopathy $(P=0.049)$ had a strong association with 5 -year event-free survival. Using multivariate model, only weight for height among under five remained significantly associated with induction deaths $(P=0.021)$ and absence of lymphadenopathy with event-free 5 -year survival $(P=0.042)$. Context: ALL has 5 -year survival of $>90 \%$ in many advanced cancer research institutes. However, advanced care is not available to majority of poor in the periphery of developing countries. Data available on the survival and the factors affecting the outcome among patients treated in poor resource settings are limited. Aims: This study aims to find the 5-year survival rate and the factors for risk-directed therapy in the region. Settings and Design: Cross-sectional analytical study at a tertiary center of public health in central Kerala. Subjects and Methods: Retrospective analysis of case sheets of 75 children who were treated at the institute from March 2006 to March 2011. Statistical Analysis Used: Univariate and Multivariate analysis using IBM SPSS Statistics for Windows, Version 20.0. Results: Of the 75 individuals studied, $11 \%$ of the children were stunted, $>21 \%$ were underweight, and $16 \%$ of the under-five children had acute malnutrition. Massive hepatosplenomegaly and lymphadenopathy were present in $75 \%$ and $77 \%$ children, respectively. About $71 \%$ patients achieved CR. A total of $30(40 \%)$ children lived for $>5$ years after diagnosis and $21(28 \%)$ of them had event-free 5 years. Weight for height for under-five children $(P=0.029)$ and total count $(P=0.019)$ were found to be significantly associated with deaths during induction. Weight for age $(P=0.024)$, weight for height of under-five children $(P=0.009)$, and lymphadenopathy $(P=0.049)$ had a strong association with 5-year event-free survival. Using multivariate model, only weight for height among under five remained significantly associated with induction deaths $(P=0.021)$ and absence of lymphadenopathy with event-free 5 -year survival $(P=0.042)$. Conclusions: Overall survival was $40 \%$ and event-free survival was $28 \%$. Children with acute malnutrition and a higher white blood cell count were more likely to die during induction. Underweight children, malnourished children, and children with lymphadenopathy had significantly poor chances of surviving 5 years' event free.
\end{abstract}

Keywords: Acute lymphoblastic leukemia, Kerala, risk-directed therapy, survival

\section{Introduction}

5-year overall survival of acute lymphoblastic leukemia (ALL) is $>90 \%$ at many advanced centers..$^{[1,2]}$ In India, survival rates vary from $36 \%$ to $53 \%$, reflecting limitations in health care, differences in general health, and probably

\footnotetext{
This is an open access journal, and articles are distributed under the terms of the Creative Commons Attribution-Non Commercial-ShareAlike 4.0 License, which allows others to remix, tweak, and build upon the work non-commercially, as long as appropriate credit is given and the new creations are licensed under the identical terms.
}

For reprints contact: reprints@medknow.com the biology of ALL. ${ }^{[3-5]}$ Treatment of leukemia had been marked by risk factors whose prognostic utility has decreased with development of specific diagnostic modalities. Unfortunately, many cases do not possess features known to warrant such specific therapy. ${ }^{[6,7]}$ Further, few of the cytogenetic and molecular studies are outside scope of many cancer treating centers in developing countries. ${ }^{[8,9]}$ Hence,

How to cite this article: Varghese B, Joobomary AA, Savida P. Five-Year survival rate and the factors for risk-directed therapy in acute lymphoblastic leukemia. Indian J Med Paediatr Oncol 2018;39:301-6.

\section{Bibin Varghese, Austoria Abzalon Joobomary ${ }^{1}$, P Savida}

Department of Paediatrics, Institute of Child Health,

${ }^{1}$ Department of Community Medicine, Government Medical College, Kottayam, Kerala, India

Address for correspondence: Dr. Bibin Varghese, Poikayil, Neethi Nagar 32-A, Pattathanam Post Office, Kollam - 691 021, Kerala, India.

E-mail: bibinvarghese92 @hotmail.com

Access this article online Website: www.ijmpo.org DOI: 10.4103/ijmpo.ijmpo_9_17 Quick Response Code:

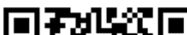


generalized methods of risk assessment are valid in these parts of the world. This study aims to find 5-year survival and factors for risk-directed therapy in the region.

\section{Subjects and Methods}

Data were obtained from case records of all children who were diagnosed of ALL and treated at the institute from March 2006 to March 2011 and were analyzed. Children referred to higher center, children whose details were not available for the entire period studied, and those who denied consent to participate in the study were excluded from the study. Diagnosis of ALL was confirmed by examination of bone marrow aspiration specimen. Cytochemistry (sudan black, PAS, MPO) was done in all cases. Immunohistochemistry which was not available at the hospital could be performed only in a handful of patients who were willing to do it outside. Cytogenetic studies were outside the reach of our institute.

Personal details such as age at diagnosis, sex, and socioeconomic status (Kuppuswamy classification) $;^{[10,11]}$ anthropometric measures such as height for age, weight for age, and weight for height; clinical features such as lymphadenopathy (any patient with >one palpable lymph node $>2 \mathrm{~cm}$ in size was considered to have lymphadenopathy), massive hepatosplenomegaly (massive hepatosplenomegaly includes either massive hepatomegaly and/or massive splenomegaly, both defined clinically, a massive hepatomegaly defined as lower border of liver palpable $>$ five fingerbreadths below the right costal margin and massive splenomegaly defined as spleen crossing the umbilicus), mediastinal mass (supported by $\mathrm{X}$-ray/computed tomography reports), central nervous system (CNS) involvement (defined as cerebrospinal fluid pleocytosis and/or cranial nerve palsies); laboratorial characteristics such as white blood cell (WBC) count at presentation, platelet count at presentation, hemoglobin count at presentation, French-American-British (FAB) class, and immunophenotype were available from the case records.
There was no definite hospital protocol on the chemotherapeutic regimens to be followed, and patients were treated using one of the three protocols summarized in Table 1. Bone marrow examination was done at the end of first induction cycle to assess response to chemotherapy. The absence of clinical evidence of disease with a blast count $<$ five percent in the background of a normocellular marrow was defined as complete remission (CR). Deaths during induction, complications, number of relapses, years of survival, and cause of death were documented after serial study of individual's case records and other hospital records (cancer registers, inpatient/outpatient records).

The data collected were entered in Microsoft Excel 2007, Version 12.0 (Redmond, WA: Microsoft Corp.), and further analysis was done in IBM SPSS Statistics for Windows, Version 20.0 (Armonk, NY, USA: IBM Corp.). Age, WBC count, platelet count, and hemoglobin were logarithmically transformed and treated as continuous variables. Socioeconomic classification was based on Kuppuswamy's socioeconomic status scale revision for $2011 .^{[10,11]}$ Height for age, weight for age, and weight for height (for under five) were computed using revised IAP growth charts 2015 (weight for height of children $>5$ years had a different categorization as per IAP charts 2015 and was therefore excluded). ${ }^{[2]}$

Frequencies of all variables were studied to understand the characteristics of the disease in the population. Associations between variables and $\mathrm{CR}$ and between variables and induction deaths were also studied. Event-free survival at 5 years was defined as the absence of events (induction failure, deaths during induction, relapse, or death during remission) for the entire 5-year period studied. Variables were also studied for their association with event-free survival at 5 years. All associations were examined on cross tabs using Pearson Chi-square test and Fischer's exact test. To make study of associations more meaningful, height for age, weight for age, and weight for height were transformed into two classes (two standard deviations below normal and above). Weight for height and immunophenotype were censored to exclude "no data available" categories.

\begin{tabular}{|c|c|c|c|}
\hline Protocols & Triple IT & BFM protocol III A & MCP 841 \\
\hline Induction & $\begin{array}{l}\text { Vincristine, prednisolone, } \\
\text { l-asparaginase (adriamycin/ } \\
\text { cyclophosphamide in high-risk } \\
\text { patients) }\end{array}$ & $\begin{array}{l}\text { Vincristine, prednisolone, } \\
\text { l-asparaginase, } \\
\text { cyclophosphamide, } \\
\text { cytarabine, daunorubicin, } \\
\text { methotrexate }\end{array}$ & $\begin{array}{l}\mathrm{I}_{1} \\
\text { Prednisolone, Vincristine, Methotrexate, } \\
\text { L-asparaginase, daunorubicin } \\
\mathrm{I}_{2} \\
\text { Mercaptopurine, cyclophosphamide, methotrexate }\end{array}$ \\
\hline $\begin{array}{l}\text { CNS } \\
\text { prophylaxis }\end{array}$ & $\begin{array}{l}\text { Intrathecal cytarabine, } \\
\text { hydrocortisone and methotrexate }\end{array}$ & $\begin{array}{l}\text { Cranial irradiation, } \\
\text { intrathecal methotrexate }\end{array}$ & Cranial irradiation, intrathecal methotrexate \\
\hline Reinduction & - & Same as induction & Same as $\mathrm{I}_{1}$ \\
\hline Maintenance & $\begin{array}{l}\text { Daily mercaptopurine, weekly } \\
\text { methotrexate, monthly vincristine } \\
\text { and prednisolone, triple IT on } \\
\text { alternate months }\end{array}$ & $\begin{array}{l}\text { Daily mercaptopurine, } \\
\text { weekly methotrexate, } \\
\text { monthly vincristine, and } \\
\text { prednisolone }\end{array}$ & $\begin{array}{l}\text { Vincristine and daunorubicin on day } 1 \text {, } \\
\text { L-asparaginase on days } 1,3,5 \text { and } 7 \text {, daily } \\
\text { mercaptopurine*, weekly methotrexate' }\end{array}$ \\
\hline
\end{tabular}

Mercaptopurine *3 weeks out of every 4 weeks for a total of 12 weeks, methotrexate' once a week, missing every $4^{\text {th }}$ week for 12 weeks 
Variables which were found statistically significant in univariate analysis were further analyzed using logistic binary regression for multivariate analysis.

\section{Results}

Of the seventy-five individuals studied, $82.7 \%$ had age between 1 and 9 years, the median age of presentation being 4 years [Table 2]. Males contributed to two-third of the study population. About $11 \%$ of the children were stunted and $>21 \%$ were underweight. Sixteen percent of the under-five children had acute malnutrition with four among them having severe acute malnutrition. Massive hepatosplenomegaly and lymphadenopathy were present in $56(74.7 \%)$ and $58(77.3 \%)$ children, respectively. Mediastinal mass was found in eight percent and CNS involvement in four percent of the cases. Fifty-nine percent belonged to $\mathrm{FAB}$ class $\mathrm{ALL} \mathrm{L}_{1}$, forty percent to $\mathrm{ALL} \mathrm{L}_{2}$, and one percent to ALL $\mathrm{L}_{3}$ [Table 3].

At the end of first induction cycle, 53 (70.7\%) patients achieved CR [Table 4]. Thirteen children died during induction due to hemorrhage and/or infections and one

\begin{tabular}{|c|c|}
\hline \multicolumn{2}{|c|}{$\begin{array}{c}\text { Table 2: Clinical characteristics of } 75 \text { previously } \\
\text { untreated patients at presentation }\end{array}$} \\
\hline Characteristics & $\begin{array}{c}\text { Total number } \\
75(100 \%) \\
\end{array}$ \\
\hline \multicolumn{2}{|l|}{ Age (years) } \\
\hline$<1$ & $5(6.7)$ \\
\hline $1-9$ & $62(82.7)$ \\
\hline$\geq 10$ & $8(10.7)$ \\
\hline \multicolumn{2}{|l|}{ Sex } \\
\hline Male & $47(62.7)$ \\
\hline Female & $28(37.3)$ \\
\hline \multicolumn{2}{|l|}{ Height for age } \\
\hline$<1^{\text {st }}$ percentile/severely stunted & $6(8.0)$ \\
\hline $1-3^{\text {rd }}$ percentile/stunted & $2(2.7)$ \\
\hline $3-50^{\text {th }}$ percentile & $46(61.3)$ \\
\hline $50^{\text {th }}-97^{\text {th }}$ percentile & $19(25.3)$ \\
\hline$\geq 97^{\text {th }}$ percentile & $2(2.7)$ \\
\hline \multicolumn{2}{|l|}{ Weight for age } \\
\hline$<1^{\text {st }}$ percentile/severely underweight & $9(12.0)$ \\
\hline $1-3^{\text {rd }}$ percentile/underweight & $7(9.3)$ \\
\hline $3-50^{\text {th }}$ percentile & $49(65.3)$ \\
\hline $50^{\text {th }}-97^{\text {th }}$ percentile & $9(12.0)$ \\
\hline$\geq 97^{\text {th }}$ percentile & $1(1.3)$ \\
\hline \multicolumn{2}{|l|}{ Weight for height (under 5) } \\
\hline$<1^{\text {st }}$ percentile/severe acute malnutrition & $4(5.3)$ \\
\hline $1-3^{\text {rd }}$ percentile/moderate acute malnutrition & $8(10.7)$ \\
\hline $3-50^{\text {th }}$ percentile & $26(34.7)$ \\
\hline $50^{\text {th }}-99^{\text {th }}$ percentile & $9(12.0)$ \\
\hline$\geq 99^{\text {th }}$ percentile/obese & $2(2.7)$ \\
\hline Lymphadenopathy & $58(77.3)$ \\
\hline Massive hepatosplenomegaly & $56(74.7)$ \\
\hline Mediastinal mass & $6(8.0)$ \\
\hline CNS involvement & $3(4.0)$ \\
\hline
\end{tabular}

child died due to hepatitis. Among the 29 (38.7\%) patients who relapsed, one had testicular relapse, four had CNS relapse, and rest had bone marrow relapse. Fifteen children died during relapse, the single most important cause being infection. To be also noted are the 17 children who died during remission; infections alone lead to death in ten of these children, 3 died due to bleeding and infections, while 4 died due to other causes (hemorrhage -1 , hepatitis -1 , hemorrhage and congestive cardiac failure $(\mathrm{CCF})-1$, and infections and $\mathrm{CCF}-1)$. A total of $30(40 \%)$ children lived for $>5$ years after diagnosis and $21(28 \%)$ of them had event-free 5 years.

\section{Univariate analysis}

None of the parameters studied had a statistically significant association with the CR [Table 5]. Weight for height for under-five children $(P=0.029)$ and total count $(P=0.019)$ were found to be significantly associated with deaths during induction [Table 6]. Children with acute malnutrition and a higher WBC count were more likely to die during induction. Age, sex, socioeconomic class, height for age, weight for age, clinical, and laboratorial characteristics other than total count did not have a significant effect on induction deaths.

Weight for age $(P=0.024)$, weight for height of under-five children $(P=0.009)$, and lymphadenopathy $(P=0.049)$ had a strong evidence of association with 5-year event-free survival [Table 7]. Underweight children, malnourished children, and children with lymphadenopathy had significantly poor chances of surviving 5 years' event free. Age, sex, socioeconomic class, height for age,

\begin{tabular}{|c|c|}
\hline Characteristics & Total number $75(100 \%)$ \\
\hline \multicolumn{2}{|c|}{ Total count (per $\mathrm{mm}^{3}$ ) } \\
\hline$<10,000$ & $40(53.3)$ \\
\hline $10,000-50,000$ & $23(30.7)$ \\
\hline$>50,000$ & $12(16.0)$ \\
\hline \multicolumn{2}{|c|}{ Platelet count (per $\mathrm{mm}^{3}$ ) } \\
\hline$<10,000$ & $2(2.7)$ \\
\hline $10,000-100,000$ & $54(72.0)$ \\
\hline$>100,000$ & $19(25.3)$ \\
\hline \multicolumn{2}{|c|}{ Hemoglobin $\left(\right.$ per $\mathrm{mm}^{3}$ ) } \\
\hline$\leq 6$ & $27(36.0)$ \\
\hline$>6-\leq 8$ & $19(25.3)$ \\
\hline$>8$ & $29(38.7)$ \\
\hline \multicolumn{2}{|l|}{ FAB class } \\
\hline ALL L $_{1}$ & $44(58.7)$ \\
\hline $\mathrm{ALL} \mathrm{L}_{2}$ & $30(40.0)$ \\
\hline $\mathrm{ALL} \mathrm{L}_{3}$ & $1(1.3)$ \\
\hline \multicolumn{2}{|l|}{ Immunophenotype* } \\
\hline Pre B-cell & $5(6.7)$ \\
\hline T-cell & $4(5.3)$ \\
\hline
\end{tabular}


clinical characteristics other than lymphadenopathy, and laboratorial characteristics did not have a significant impact on the 5-year event-free survival.

\section{Multivariate analysis}

When the significant factors from univariate analysis were studied using multivariate model, only weight for height among under five remained significantly associated with

Table 4: Frequency of various events among the 75 children studied

\begin{tabular}{lc}
\hline Events & Total number 75 (100\%) \\
\hline Complete remission & $53(70.7)$ \\
Deaths during induction & $13(17.3)$ \\
Hemorrhage and infections & 9 \\
Infections & 2 \\
Hemorrhage & 1 \\
Hepatitis & 1 \\
Relapse & $29(38.7)$ \\
Deaths during relapse & $15(20.0)$ \\
Infections & 8 \\
Seizures & 3 \\
Hemorrhage and infections & 2 \\
Hemorrhage & 1 \\
Infections and CCF & 1 \\
Deaths during remission & $17(22.7)$ \\
Infections & 10 \\
Hemorrhage and Infections & 3 \\
Hemorrhage & 1 \\
Hepatitis & 1 \\
Hemorrhage and CCF & 1 \\
Infections and CCF & 1 \\
Overall survival (5 years) & $30(40.0)$ \\
Event free survival (5 years) & $21(28.0)$ \\
\hline CCF - Cleveland clinic foundation &
\end{tabular}

$\mathrm{CCF}$ - Cleveland clinic foundation

\begin{tabular}{lc}
\hline \multicolumn{2}{c}{ Table 5: Relationship of various characteristics to } \\
complete remission
\end{tabular}

induction deaths $(P=0.021)$. Similarly, only absence of lymphadenopathy was found to be significantly associated with event-free 5-year survival $(P=0.042)$.

\section{Discussion}

Leukemia treatment in developing countries is peculiar for number of reasons. Clinical variances, adverse socioeconomic, cultural, and political influences make establishment of resources, procurement of drugs, and timely intervention difficult. Even when the most advanced centers of cancer care have survival $>90 \%{ }^{[1,2]}$ they seem distant to the poor resource settings in developing countries. However, recently, specialized centers of cancer care within

\begin{tabular}{lc}
\hline \multicolumn{2}{c}{ Table 6: Relationship of various characteristics to } \\
induction deaths
\end{tabular}

CNS - Central nervous system; FAB - French-American-British

\section{Table 7: Relationship of various characteristics to} event-free survival

\begin{tabular}{lc}
\hline Characteristics & Univariate $\boldsymbol{P}$ value \\
\hline Age & 0.817 \\
Sex & 0.188 \\
Kuppuswamy class & 0.798 \\
Height for age & 0.282 \\
Weight for age & 0.024 \\
Weight for height under 5 & 0.009 \\
Lymphadenopathy & 0.049 \\
Massive hepatosplenomegaly & 0.239 \\
Mediastinal mass & 0.458 \\
CNS involvement & 0.633 \\
Total count & 0.061 \\
Platelet count & 0.443 \\
Hemoglobin & 0.259 \\
FAB class & 0.597 \\
Immunophenotype & 0.278 \\
Treatment regimen & 0.602 \\
\hline CNS - Central nervous system; FAB - French-American-British
\end{tabular}


India have started showing promising results. ${ }^{[13,14]}$ Recently, specialized many refuse referrals to these centers as they cannot afford to move to such locations and that it would mean not being able to simultaneously support family back home.

The multitude of factors previously described often leads to a late diagnosis of the disease. In addition, potential genetic differences and biology of ALL also contribute to the clinical picture at presentation. This study shows that males are more affected than females with a ratio of 1.7:1. The median age of presentation was found to be 4 years, a year higher than that described in western literatures. ${ }^{[1]}$ However, contradictory to the popular teachings, age was not directly associated with 5 -year event-free survival. This is however in line with drawings from Indian studies, ${ }^{[8]}$ opening the question whether age should be considered as factor for risk stratification in our population. Age and sex also did not show any associations with treatment response and deaths during induction.

Kuppuswamy classification was the tool used to categorize socioeconomic class. All children belonged either to the lower/upper lower, middle/lower middle, and upper middle classes of Kuppuswamy classification. Lower/upper lower made $55 \%$ of the individuals. The data show that even for the upper middle class $(15 \%)$, ours was the only treatment available/accessible. However, socioeconomic status did not have any significant effect on the outcomes.

Nutritional factors and concurrent infections are among the important factors adversely affecting survival in developing countries. They also influence toxicity of therapy due to effects on drug metabolism and excretion. ${ }^{[15-18]} \mathrm{A}$ significant effort was made to study this relationship in our series. Results suggest that under-five children with acute malnutrition were more likely to die during induction and have poor chances of surviving 5 years' event free. Children who were underweight also showed similar association with event-free 5-year survival.

Almost $80 \%$ of the children had lymphadenopathy and about $75 \%$ of them had massive hepatosplenomegaly. Hepatomegaly had long been included as a risk factor in BFM protocols; however, lymphadenopathy, being less common, had not been studied. ${ }^{[3]}$ Our study shows significant association between absence of lymphadenopathy and event-free 5-year survival. Whether this lymphadenopathy is the result of delayed diagnosis or due to the genetic, environmental, or biologic variations in the population remains unclear. Mediastinal mass and CNS involvement were found to be less frequent in our setting. Mediastinal mass, CNS involvement, and massive hepatosplenomegaly were not found to have a significant effect on outcomes.

The proportion of patients with total count $>50,000$ remained comparable to other studies. ${ }^{[3]}$ Although there was a trend that total count $>50,000$ was associated with decreased event-free 5-year survival, it was not found to be significant $(P=0.061)$. However, a high total count at presentation was significantly associated with deaths during induction. Such trend was previously described, in the study by Rubnitz et al. at St. Jude hospital. ${ }^{[19]}$ Platelet count, hemoglobin, and FAB class were not found to have significant effect on treatment response, induction deaths, or survival.

Immunophenotyping results could be obtained only for 9 patients during the period studied. Among the available nine, four had T-cell ALL. This suggests higher proportion of T-cell ALL in Kerala, like in other parts of the country. ${ }^{[4,8,20,21]}$

Three treatment regimens were simultaneously used during the 5 years studied. None superior in terms of response to treatment or event-free 5-year survival. Each one contributed roughly the same to induction deaths.

The multitude of factors impeding the treatment had resulted in decreased survival rates compared to advanced centers within India and the world. Patients who achieved remission were considerably less (70\%) and induction deaths were substantially high (17\%). Study of the characteristics of leukemia shows that the population is much different from their western counter parts. And thus, foreign protocols need to be tailored considering the differences in our population, to increase survival and decrease toxicity. Further studies on the clinical and laboratorial characteristics of the disease and their associations with survival and toxicity are essential for formulating such modifications. Amid the adverse factors, an overall survival of $40 \%$ at 5 years, in a poor resource setting, is inspirational to further provide quality cancer care. By making specialized healthcare more accessible and giving financial support to needy, we can improve the life of many more. Twinning has been described as one other strategy to improve cancer care in developing countries. ${ }^{[5,22,23]}$ This can also be tried within the country to make cancer care more accessible.

\section{Financial support and sponsorship}

Nil.

\section{Conflicts of interest}

There are no conflicts of interest.

\section{References}

1. Frehling E, Ritchey AK, Tubergen DG, Bleyer A. Acute lymphoblastic leukaemia. In: Kliegman RM, Stanton B, Geme JS, Schor NF, editors. Nelson Textbook of Paediatrics. $1^{\text {st }}$ ed., Vol. 495. South Asia: Elsevier Health Sciences; 2015. p. $2437-42$.

2. Hunger SP, Lu X, Devidas M, Camitta BM, Gaynon PS, Winick NJ, et al. Improved survival for children and adolescents with acute lymphoblastic leukemia between 1990 and 2005: 
A report from the children's oncology group. J Clin Oncol 2012;30:1663-9.

3. Advani S, Pai S, Venzon D, Adde M, Kurkure PK, Nair CN, et al. Acute lymphoblastic leukemia in India: An analysis of prognostic factors using a single treatment regimen. Ann Oncol 1999;10:167-76.

4. Kapoor A, Kalwar A, Kumar N, Singhal MK, Beniwal S, Kumar HS, et al. Analysis of outcomes and prognostic factors of acute lymphoblastic leukemia patients treated by MCP841 protocol: A regional cancer center experience. J Res Med Sci 2016;21:15.

5. Menon J, Mathews L, Purushothaman KK. Treating leukemia in a resource poor setting. Indian Pediatr 2008;45:410-2.

6. Pui CH. Acute Lymphoblastic Leukemia. Hong Kong J Paediatr (New Series) 1996;1:5-13. Available from: http://www. hkjpaed.org/details.asp?id $=434 \&$ show $=1234$. [Last accessed on 2016 Dec 16].

7. Pui CH, Crist WM. Biology and treatment of acute lymphoblastic leukemia. J Pediatr 1994;124:491-503.

8. Magrath I, Shanta V, Advani S, Adde M, Arya LS, Banavali S, et al. Treatment of acute lymphoblastic leukaemia in countries with limited resources; lessons from use of a single protocol in India over a twenty year period [corrected]. Eur J Cancer 2005;41:1570-83.

9. Arora RS, Eden TO, Kapoor G. Epidemiology of childhood cancer in India. Indian J Cancer 2009;46:264-73.

10. Kuppuswamy B. Manual of Socioeconomic Status (urban). Delhi: Manasayan; 1981.

11. Sharma R. Kuppuswamy's socioeconomic status scale - Revision for 2011 and formula for real-time updating. Indian J Pediatr 2012;79:961-2.

12. Indian Academy of Pediatrics Growth Charts Committee, Khadilkar V, Yadav S, Agrawal KK, Tamboli S, Banerjee M, et al. Revised IAP growth charts for height, weight and body mass index for 5- to 18-year-old Indian children. Indian Pediatr 2015;52:47-55.

13. Kulkarni KP, Arora RS, Marwaha RK. Survival outcome of childhood acute lymphoblastic leukemia in India:
A resource-limited perspective of more than 40 years. J Pediatr Hematol Oncol 2011;33:475-9.

14. Yadav SP, Kalra M, Anjan M, Sachdeva A. Survival outcome in childhood acute lymphoblastic leukemia in India. Pediatr Blood Cancer 2010;54:178.

15. Lobato-Mendizábal E, Ruiz-Argüelles GJ, Marín-López A. Leukaemia and nutrition. I: Malnutrition is an adverse prognostic factor in the outcome of treatment of patients with standard-risk acute lymphoblastic leukaemia. Leuk Res 1989;13:899-906.

16. Viana MB, Murao M, Ramos G, Oliveira HM, de Carvalho RI, de Bastos $\mathrm{M}$, et al. Malnutrition as a prognostic factor in lymphoblastic leukaemia: A multivariate analysis. Arch Dis Child 1994;71:304-10.

17. Dutta U, Raina V, Garg PK, Gurbuxani S, Joshi YK, Bhargava M, et al. A prospective study on the incidence of hepatitis B \& C infections amongst patients with lymphoproliferative disorders. Indian J Med Res 1998;107:78-82.

18. Nag S, Vadya S, Pai S. Hepatitis B viral infection in All. Indian J Haematol Bid Trans 1995;13:150-3.

19. Rubnitz JE, Lensing S, Zhou Y, Sandlund JT, Razzouk BI, Ribeiro RC, et al. Death during induction therapy and first remission of acute leukemia in childhood: The St. Jude experience. Cancer 2004;101:1677-84.

20. Rajalekshmy KR, Abitha AR, Pramila R, Gnanasagar T, Shanta V. Immunophenotypic analysis of T-cell acute lymphoblastic leukaemia in Madras, India. Leuk Res 1997;21:119-24.

21. Mukhopadhyay A, Gangopadhyay S, Dasgupta S, Paul S, Mukhopadhyay S, Ray UK, et al. Surveillance and expected outcome of acute lymphoblastic leukemia in children and adolescents: An experience from Eastern India. Indian J Med Paediatr Oncol 2013;34:280-2.

22. Hunger SP, Sung L, Howard SC. Treatment strategies and regimens of graduated intensity for childhood acute lymphoblastic leukemia in low-income countries: A proposal. Pediatr Blood Cancer 2009;52:559-65.

23. Veerman AJ, Sutaryo S, Sumadiono S. Twinning: A rewarding scenario for development of oncology services in transitional countries. Pediatr Blood Cancer 2005;45:103-6. 